
phenolic compounds composition, antioxidant activity and bioavailability of phenols in dried thistle flower. Journal of Food Measurement and Characterization, 11(1), 192203.

\title{
EVALUATION OF PHENOLIC COMPOUNDS COMPOSITION, ANTIOXIDANT ACTIVITY AND BIOAVAILABILITY OF PHENOLS IN DRIED THISTLE FLOWER
}

\section{Raquel P. F. Guiné ${ }^{1 *}$, Ana Pedro ${ }^{2}, J_{0 a n a}$ Matos $^{3}$, Paulo Barracosa ${ }^{4}$, Cláudia Nunes 5 , Fernando J. Gonçalves ${ }^{6}$}

\footnotetext{
${ }^{1}$ CI\&DETS, Instituto Politécnico de Viseu, Campus Politécnico, Viseu, Portugal; CERNAS, Escola Superior Agrária de Coimbra, Portugal (raquelguine@esav.ipv.p)

${ }^{2}$ Escola Superior Agrária de Viseu, Quinta da Alagoa, Viseu, Portugal (apedrinha@ hotmail.com)

${ }^{3}$ Escola Superior Agrária de Viseu, Quinta da Alagoa, Viseu, Portugal (jmatos@bmc.com.pt)

${ }^{4}$ Escola Superior Agrária de Viseu, Quinta da Alagoa, Viseu, Portugal (pbarracosa@esav.ipv.pt)

${ }^{5}$ CICECO and QOPNA, Universidade de Aveiro, Campus de Santiago, Aveiro, Portugal (claudianunes@ua.pt)

${ }^{6}$ CI\&DETS, Instituto Politécnico de Viseu, Campus Politécnico, Viseu, Portugal; (fernandogoncalves@esav.ipv.p)
}

*Corresponding author:

\section{Raquel P. F. Guiné}

Dep. Indústrias Alimentares, ESAV, Quinta da Alagoa, Estrada de Nelas, Ranhados, 3500606 Viseu, Portugal.

Phone: +351 232480700; Fax:+351 232480750; E-mail: raquelguine@esav.ipv.pt 


\begin{abstract}
The objective of this work was to characterize the thistle flower in relation to the composition of phenolic compounds and antioxidant activity, as well as the evaluation of the stability of the phenols along the digestive tract. In addition, the effect of drying temperature was evaluated and the composition in polysaccharides was also studied. For this, samples of thistle flower were lyophilized and dried at 40, 50 and $60{ }^{\circ} \mathrm{C}$. Methanol:acetic acid (98:2 v/v) and acetone:water $(60: 40 \mathrm{v} / \mathrm{v})$ extracts were obtained and analysed for antioxidant activity, phenolic compounds, ortho-diphenols, flavonoids, phenolic acids and polysaccharides, using colorimetric methods, HPLC and GC-FID. The results showed that the phenolic compounds and antioxidant activity with ABTS or DPPH methods on thistle flower decreased by $20 \%$, $34 \%$ and $72 \%$, respectively, with increasing temperature from 40 to $60{ }^{\circ} \mathrm{C}$. The amount of compounds available for intestinal absorption decreased along the gastrointestinal system, by $15 \%$ to $50 \%$. The presence of sugars constituent of pectic polysaccharides was observed $(101.6-222.0 \mathrm{mg} / \mathrm{g})$ as well as of hydroxybenzoic $(0.19-1.26 \mathrm{mg} / \mathrm{g})$ and hydroxycinnamic acids $(1.57-5.59 \mathrm{mg} / \mathrm{g})$. As a conslusion it was found that thistle flower is rich in bioactive compounds with potential importance for the human health.
\end{abstract}

Keywords Antioxidant activity . Bioavailability . Drying, Phenolic compounds . Thistle flower . 


\section{Introduction}

Phenolic compounds are widely spread in the plant kingdom, and may have simple or complex structures, being essential for growth and reproduction of plants, in addition to being responsible for defense mechanisms and contributing in pigmentation. Besides, they are also involved in processes responsible for the color, flavor and astringency in several foods [1]. Structurally, they can be divided into flavonoids and non-flavonoids. The non-flavonoids are numerous and variable in composition among different species and may occur esterified with sugars, alcohols, organic acids, or tartaric acid. Flavonoids include catechins, proanthocyanidins and anthocyanins. They may appear both in the free form or polymerized with other phenolic compounds or sugars [2]. According to Falleh et al. [3], thistle (Cynara cardunculus L.) presents a large amount of phenolic compounds, being higher in the seeds than in the leaves and flowers. However the concentration of these compounds varies depending on the species and environmental conditions [4].

The thistle belongs to the family Asteraceae, with a variety of genres, including the genus Cynara L. consisting of eight species: C. cardunculus L., C. syriaca Boiss., C. auranitica Post, C. cornigera Lindley, C. algarbiensis Cosson, C. baetica (Spreng.) Pau, C. cyrenaica Maire et Weiller, and $C$. humilis L. The thistle (Cynara cardunculus L.) grows in rocky sites and can be found both in the wild or cultivated [5].

The thistle is used for medicinal treatments, as it is a rich source of phenolic compounds, due to their antioxidant activity. Thistle plant assumes importance due to its therapeutic potential in the treatment of liver diseases; diabetes, lowering cholesterol and blood sugar; digestive, urinary or rheumatic problems; stomach and intestinal disorders; cancer; anaemia, etc. [3,6]. It is also used in aesthetic medicine, as anti-cellulite and in creams for skin aging. The phenolic compounds are antioxidants, fight cellular aging (free radicals), prevent diseases, inhibit lipid 
oxidation and proliferation of fungi. Health benefits of phenolic compounds include cardioprotection effect, antinflamatory and antiviral activities, antimutagenic and anticarcinogenic effects and antiaging, preventing several neurodegerative disorders [7-11].

Drying is a common way to preserve foods, allowing obtaining stable products in the absence of any preservatives or harmful electromagnetic radiation exposure. The drying is a very complex process, in which occur simultaneously mass and heat transfer phenomena [12] leading to structural changes at the physical and chemical levels in the products. The drying of plants is a crucial process that aims to bring them to low moisture contents, allowing preservation, while maintaining the physical and chemical quality for a longer time. However, if the residual moisture content is above $10 \%$, it can favor the development of fungi and bacteria, as well as enable the hydrolytic activity of several enzymes present in plant cells, leading to the oxidation and degradation of the active compounds and may thus influence their biological activity. Thus, the application of appropriate drying methodologies for each species is necessary to preserve the active substances $[9,13,14]$.

In Portugal, the thistle flower of C. cardunculus L., Cynara gender, is widely used in the manufacture of various cheeses, including the Serra da Estrela cheese. This is used, after a drying process, as milk coagulant due to the presence of aspartic proteinases [5]. Traditionally, drying of the thistle flower for the production of cheese is made in the shade, in a cool and airy place, spread on trays that should be stirred periodically [5]. This process shows, however, some problems, either by remaining excessive time under oscillating weather conditions or due to the presence of fauna, in particular insects, which may result in significant damage to the final product.

This study aimed to quantify and identify the phenolic compounds and antioxidant activity, as well as their bioavailability, on the thistle flower of $C$. cardunculus $\mathrm{L}$ subjected to different drying treatments, to evaluate the best drying conditions to maintain the biological activity. 
The polysaccharides content was also studied in order to evaluate the feasibility to enlarge the applications of the dried thistle flowers.

\section{Materials and Methods}

\section{Samples}

The samples of thistle flower used in this study were of the species Cynara cardunculus L. harvested in the centre region of Portugal, in Oliveira do Hospital, in ANCOSE (National Association of Breeders of Sheep Serra da Estrela) at the time of flowering, in June.

\section{Processing of the Thistle Flower}

The thistle flowers were dried at different temperatures $\left(40{ }^{\circ} \mathrm{C}, 50{ }^{\circ} \mathrm{C}\right.$ and $\left.60{ }^{\circ} \mathrm{C}\right)$ in a forced convection chamber set at the desired temperature. The chamber used was a WTB Binder, with an air speed of $0.5 \mathrm{~m} / \mathrm{s}$. Every $15 \mathrm{~min}$ a sample was taken in order to control the moisture content. Moisture was determined on a Halogen Moisture Analyser HG53 from Mettler Toledo and the final water activity was measured by a hygrometer Novasina LabMaster AW from Novatron. Each drying process was completed when the sample reached a final moisture content of $1 \%$. From these processes resulted 3 samples, designated as D40, D50 and D60, for the thistle dried at 40,50 and $60{ }^{\circ} \mathrm{C}$, respectively. In parallel, the thistle flower was frozen in a conventional freezer and then lyophilized at $-50{ }^{\circ} \mathrm{C}$ and $0.7 \mathrm{~Pa}$. The sample resulting from lyophilization was designated as L.

\section{Extraction of Phenolic Compounds}

The extraction of phenolic compounds from thistle was performed by adaptation of the procedure described by Guiné et al. [9]. To each sample (L, D40, D50 and D60) was added $100 \mathrm{~mL}$ of a solution methanol:acetic acid $(98: 2 \mathrm{v} / \mathrm{v})$ and the extraction was carried out under stirring for 1 hour, being the liquid fraction collected by filtration. This process was repeated 
two more times to give the methanol extracts (ME). The solid residue insoluble in methanol resulting from the previous extractions was used for the following extractions with acetone:water $(60: 40 \mathrm{v} / \mathrm{v})$. Hence, to this residue was added $100 \mathrm{ml}$ of the extraction solution, and it was kept under stirring for $1 \mathrm{~h}$, being the procedure repreated two more times The resulting extracts were designated by acetone extracts (AE). In fact, in order to optimize the extraction process, three successive extractions were performed with each of the solvents, yielding three methanol extracts (ME1, ME2, ME3) and three acetone extracts (AE1, AE2, AE3). Also two sample masses were used (5 $\mathrm{g}$ and $10 \mathrm{~g})$ to verify in which case the extraction procedure was more efficient.

\section{Determination of Phenolic Compounds}

The Folin-Ciocalteu method was used for the determination of total phenolic compounds, according to what is described by Soutinho et al. [15]. The concentrations of phenolic compounds in the extracts were obtained through a linear calibration curve obtained with gallic acid at concentrations between $0-0.5 \mathrm{~g} / \mathrm{L}$. The results were expressed in $\mathrm{mg}$ of gallic acid equivalents (GAE) per gram of thistle sample.

\section{Determination of Flavonoids}

For determining the content of flavonoids it was used an adaptation of the method described by Santos et al. [11]. The total flavonoids present in each sample were determined by spectrophotometry, with a linear calibration curve obtained with solutions of quercetin at concentrations between 0.02 and $0.20 \mathrm{~g} / \mathrm{L}$. The results were expressed in $\mathrm{mg}$ of quercetin equivalents (QE) per gram of thistle sample.

\section{Determination of Ortho-Diphenols}

The principle of the method used to determine the ortho-diphenols is based on the complexation of ortho-diphenols with molybdate ions, as described by Santos et al. [11]. The 
concentrations of ortho-diphenols were found through the linear calibration curve obtained with gallic acid in concentrations between 0-300 $\mathrm{mg} / \mathrm{L}$. The results were expressed in $\mathrm{mg}$ of gallic acid equivalens (GAE) per gram of thistle sample.

\section{Evaluation of Antioxidant Activity}

The determination of antioxidant activity was performed by the ABTS method as described in Santos et al. [11] and by the DPPH method as reported in Guiné et al. [16]. For obtaining the concentrations a linear calibration curve was prepared with the trolox in concentrations between 0.08 and $0.4 \mathrm{mmol}$. The results were expressed in mmole Trolox equivalents (TE) per gram of thistle sample.

\section{Analysis of Bioavailability}

The method used for in-vitro simulation of the various stages of the digestive system was adapted from McDougall et al. [17]. The method consists of three sequential steps, based on the solutions that simulate the condition on the digestive tract: sodium chloride $1 \%(\mathrm{~m} / \mathrm{v})$, alpha-amilase $1 \%(\mathrm{~m} / \mathrm{v})$, pepsin $1 \%(\mathrm{~m} / \mathrm{v})$, pancreatin $0.3 \%(\mathrm{~m} / \mathrm{v})$ and biliary salts $1 \%(\mathrm{~m} / \mathrm{v})$. The values of $\mathrm{pH}$ were previously adjusted to 6.5 for the $\alpha$ amylase solution, to 2 for pepsin and to 7 for pancreatin and bile salts. The in-vitro solutions were processed as follows, according to the phase of the digestive tract. Mouth: to a tube was added $1 \mathrm{~mL}$ of sample plus $1 \mathrm{ml}$ of $\alpha$-amylase solution, and then was allowed to react for 2 minutes at $37^{\circ} \mathrm{C}$. Stomach: to $1 \mathrm{ml}$ of the previous solution was added $1 \mathrm{~mL}$ of pepsin solution and allowed to react for $2 \mathrm{~h}$ at $37^{\circ} \mathrm{C}$. Intestine: to $1 \mathrm{ml}$ of the previous solution was added $1 \mathrm{ml}$ of pancreatin and bile salts solution and allowed to react for $2 \mathrm{~h}$ at $37{ }^{\circ} \mathrm{C}$. At the end of each step was assessed the concentration of phenolic compounds. Meanwhile, in each stage, control tests were performed with the same simulated conditions but without the sample. 


\section{Evaluation of Phenolic Compounds by HPLC}

The fractionation of the phenolic compounds was made from the methanol and acetone extracts obtained as described earlier, but by joining both methanol extracts (ME1 and ME2) into one single methanol extract and repeating this for the acetone extracts. This procedure was repeated for all samples.

For the fractionation of phenolic compounds mini-columns Discovery DSC-18 were used (60 $\mathrm{ml}$ capacity and $10 \mathrm{~g}$ of $\mathrm{C} 18$ filling material). The columns were activated with $100 \mathrm{~mL}$ of methanol and then washed with $100 \mathrm{~mL}$ of distilled water, followed by a preconditioning with $50 \mathrm{ml}$ of a commercial buffer solution phosphate $\mathrm{pH} 7.0$ before use. The $\mathrm{pH}$ of the sample was neutralized by adding $\mathrm{NaOH} 0.1 \mathrm{~N}$. The sample was carefully loaded onto the preconditioned C-18 column at a flow rate of less than $2 \mathrm{~mL} / \mathrm{min}$. Fractionation started by adding $100 \mathrm{~mL}$ of phosphate buffer solution $\mathrm{pH} 7.0(1: 8 \mathrm{v} / \mathrm{v})$ to elute the phenolic acids (fraction buffer). Then, the column was washed with $50 \mathrm{ml}$ of distilled water and dried under vacuum for a few seconds. Elution with $100 \mathrm{ml}$ of ethyl acetate allowed isolating the fraction comprising monomers and oligomers of procyanidins. Phenolic compounds specified in column consisting of anthocyanin pigments and polymer were finally eluted with $100 \mathrm{~mL}$ of methanol acidified with $0.1 \% \mathrm{HCl}$ (methanol extract). The extracts obtained were then concentrated in a rotary evaporator Laborota 4000 (Heydolph, Germany) until a final volume of about $2 \mathrm{ml}$.

The buffer fraction was used for the determination of phenolic acids and the methanol extraction was used for the determination of monomeric anthocyanins by high performance liquid chromatography (HPLC) with a Dionex 3000 Ultimate Chromatographic System (Sunnyvale, California, USA) equipped with a quaternary pump 46 LPG model A-3400, autosampler ACC 3000, a column compartment with thermostat (adjustable up $35{ }^{\circ} \mathrm{C}$ ) and a detector UV/Vis-300 MWD. 
The mobile phase A was an aqueous solution of $5 \%$ formic acid (used as a mobile phase to adjust the $\mathrm{pH}$ because of its volatility and acidifying properties) and mobile phase $\mathrm{B}$ was methanol, both of analytical quality (Panreac). The ultrapure water was obtained from a MilliQ water purification system (Millipore, USA). Elution took place with a flow rate of 1.0 $\mathrm{mL} / \mathrm{min}$ and the gradient used followed the steps: $0 \mathrm{~min}(95 \% \mathrm{~A}, 5 \% \mathrm{~B}) ; 5 \mathrm{~min}(95 \% \mathrm{~A}, 5 \% \mathrm{~B})$; $65 \min (40 \% \mathrm{~A}, 60 \% \mathrm{~B}) ; 70 \min (40 \% \mathrm{~A}, 60 \% \mathrm{~B}) ; 75 \min (95 \% \mathrm{~A}, 5 \% \mathrm{~B})$. The injected sample volume was $50 \mu \mathrm{L}$ at $1 \mathrm{~mL} / \mathrm{min}$ and $25^{\circ} \mathrm{C}$.

Detection was performed at 280 and $325 \mathrm{~nm}$ and Chromeleon software (version 6.8) (Sunnyvale, CA, USA) was used to delineate the chromatographic profile of phenolic acids.

\section{Analysis of Neutral Sugars}

The analysis of neutral sugars was carried out after hydrolysis of polysaccharide material with sulphuric acid (1 $\mathrm{M}$ at $100{ }^{\circ} \mathrm{C}$ during $2.5 \mathrm{~h}$ ), followed by derivatization of the sugars released to alditol acetates as described by Nunes et al. [18]. The compounds were then separated on a capillary column DB 225 in a gas chromatograph equipped with a flame ionization detector (FID). The carrier gas was hydrogen and the injector and detector temperatures were $220{ }^{\circ} \mathrm{C}$ and $230{ }^{\circ} \mathrm{C}$, respectively. The temperature program used in the assay was chosen according to the characteristics of the sample and consists in the following time/temperature conditions: 1 min at $200{ }^{\circ} \mathrm{C} ; 40{ }^{\circ} \mathrm{C}$ per min up to $220{ }^{\circ} \mathrm{C} ; 7$ min at $220{ }^{\circ} \mathrm{C} ; 20{ }^{\circ} \mathrm{C}$ per minute up to $230{ }^{\circ} \mathrm{C}$ and $1 \mathrm{~min}$ at $230{ }^{\circ} \mathrm{C}$. The sample injection volume used was $2 \mu \mathrm{L}$.

Uronic acids were quantified by a modification of the method by Nunes et al. [18]. Samples

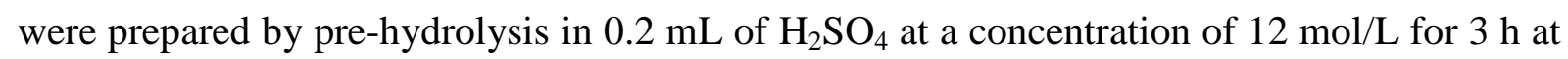
room temperature followed by hydrolysis for $1 \mathrm{~h}$ in $\mathrm{H}_{2} \mathrm{SO}_{4}$ at a concentration of $1 \mathrm{~mol} / \mathrm{L}$ at $100^{\circ} \mathrm{C}$. A linear calibration curve was made with D-galacturonic acid. 


\section{Statistical analysis}

In order to understand if the results obtained are statistically different a statistical analysis was applied. The $\mathrm{T}$ de student test was used to compare values among two groups and the ANOVA with Tukey HSD (Honestly Significant Difference) test was used to compare among three or more groups. In all cases the level of significance considered was $p<0.05$. Tukey's is a statistical test to find the results that are different from other representatively and consists of a single multi-step process for comparison, together with an analysis of variance (ANOVA).

The statistical analysis was applied to the data obtained from spectrophotometric measurements, where replicates were performed, not being applied to the data obtained from HPLC or CG chromatograms, where no replications were available.

For statistical analysis was used the statistical software SPSS Version 23 from IBM, Inc.

\section{Results and Discussion}

\section{Drying procedure}

The dehydration conditions for the different samples are described below for each case:

- $\quad$ Llyophilized (L): Processing time (PT) = 24:00 hours; initial moisture content (IMC) $=57.5 \pm 0.8 \mathrm{~g} / 100 \mathrm{~g}$ wet basis $(\mathrm{wb})$; final moisture content $(\mathrm{FMC})=1.4 \pm 0.1 \mathrm{~g} / 100 \mathrm{~g}$ $w b$; water activity $\left(\mathrm{a}_{\mathrm{w}}\right)$ of the dried samples $=0.31 \pm 0.02$;

- $\quad$ Dried at $40^{\circ} \mathrm{C}$ (D40): PT $=5: 30$ hours; $\mathrm{IMC}=56.5 \pm 0.4 \mathrm{~g} / 100 \mathrm{~g}$ wb; FMC $=1.5 \pm 0.2$ $\mathrm{g} / 100 \mathrm{~g} \mathrm{wb} ; \mathrm{a}_{\mathrm{w}}$ of the dried samples $=0.43 \pm 0.03$;

- Dried at $50^{\circ} \mathrm{C}(\mathrm{D} 50): \mathrm{PT}=4: 15$ hours; $\mathrm{IMC}=57.6 \pm 0.4 \mathrm{~g} / 100 \mathrm{~g}$ wb; FMC $=1.0 \pm 0.1$ $\mathrm{g} / 100 \mathrm{~g} \mathrm{wb} ; \mathrm{a}_{\mathrm{w}}$ of the dried samples $=0.35 \pm 0.05 ;$

- $\quad$ Dried at $60^{\circ} \mathrm{C}(\mathrm{D} 60): \mathrm{PT}=3: 15$ hours; $\mathrm{IMC}=56.8 \pm 0.5 \mathrm{~g} / 100 \mathrm{~g} \mathrm{wb} ; \mathrm{FMC}=1.0 \pm 0.1$ $\mathrm{g} / 100 \mathrm{~g} \mathrm{wb} ; \mathrm{a}_{\mathrm{w}}$ of the dried samples $=0.34 \pm 0.01$. 
For all processing conditions the final moisture content was similar, just about $1 \%$, corresponding to the removal of practically all the water initially present $(97 \%$ in samples $\mathrm{L}$ and D40 and 98\% in samples D50 and D60). The values of water activity $\left(\mathrm{a}_{\mathrm{w}}\right)$ obtained for all the samples examined are very low, meaning that they reached the primary adsorption zone in which no dissolution of the food components occurs in water, thus slowing down the reactions, with the exception of lipid oxidation, which can occur in both low and high water activity $[19,20]$. An $a_{w}$ of less than 0.6 assures stability of the product, being a key parameter for its preservation and allowing extension of its shelf life [21-23].

\section{Analysis of the extraction procedure for the phenolic compounds}

Preliminary tests were performed in order to evaluate the most efficient extraction procedure for this particular product, thistle flower. The percentage of phenolic compounds recovered in the methanol:acetic acid extracts were $57 \%, 33 \%$ and $10 \%$, respectively for the first, second and third extractions, while for the acetone:water extracts the percentages were $70 \%, 21 \%$ and 9\%, respectively for the first, second and third extractions (Figure 1). Hence, the results show that the third methanol extract accounted for only about $10 \%$ of the compounds extracted with this solvent and, similarly, the amount of compounds collected in the third acetone extract accounted for only $9 \%$ of the total phenols extracted by acetone:water. These results showed that a third extraction was not important, in view of optimizing efficiency versus time and costs, and, hence, only two extractions were performed with each solvent afterwards.

Also different tests were made in order to verify which ratio sample mass/volume of solvent should be used for the optimization of the extraction of phenolic compounds in thistle flower, being all these done in the fresh sample of thistle flower. Table 1 shows the phenolic compounds quantified in two extractions made with methanol:acetic acid solution and other two extractions made with acetone:water solution. It was found that the ratio 5:50 $(\mathrm{g}: \mathrm{mL}$ of 
solvent) would be the most suitable option for obtaining higher values of total phenols and antioxidant activity, $13.2 \mathrm{mg}$ GAE/g and 9.6 (mmol TE/g), respectively, being these significantly different $(\mathrm{p}=0.002)$ from those obtained with the ratio 10:50 (g:mL). The results further showed statistically significant differences $(p=0.000)$ in total phenols and antioxidant activity between the methanol and the acetone extracts for both ratios tested.

\section{Phenolic Compounds}

Table 2 shows the composition in phenolic compounds (total phenols, flavonoids and orthodiphenols), obtained for the methanol extracts (ME) and acetone extracts (AE) from the samples of thistle submitted to different drying treatments: lyophilized (L) and dried at $40^{\circ} \mathrm{C}$ (D40), $50^{\circ} \mathrm{C}(\mathrm{D} 50)$ and $60^{\circ} \mathrm{C}(\mathrm{D} 60)$. The amount of phenolic compounds extracted with the different solvents (acetone and methanol) was similar for samples D40 and D50 (slightly over $6 \mathrm{mg} \mathrm{GAE} / \mathrm{g}$ ), and not much different for sample D60 either (with $4.3 \mathrm{mg} \mathrm{GAE} / \mathrm{g}$ for the sum of the two methanol extracts and a little bit more in the acetone extracts, $5.9 \mathrm{mg} \mathrm{GAE} / \mathrm{g}$ ). However, statistical tests indicate that the differences were not significant $(\mathrm{p}=0.127)$ only for the samples of methanol extracts D40 and D50, being significantly different $(\mathrm{p}=0.021)$ for all acetone extract samples. In the case of sample L, $12.8 \mathrm{mg}$ GAE/g were obtained in the methanol extracts whereas in the acetone extracts only about half was encountered, $5.7 \mathrm{mg}$ GAE/g. While for the lyophilized sample $69 \%$ of the total phenolic compounds were obtained from the methanol extracts, in the samples dried by hot air a reverse trend was observed, towards a slightly higher extraction with acetone for extracts D50 and D60, ranging between 50 and $58 \%$ of the total phenols extracted.

The lyophilized thistle had the highest quantity of phenolic compounds, resulting from the sum of the methanol and acetone extracts, while the sample dried at $60{ }^{\circ} \mathrm{C}$ had the lowest (18.5 and $10.2 \mathrm{mg} \mathrm{GAE/g,} \mathrm{respectively)} \mathrm{(Table} \mathrm{2).} \mathrm{The} \mathrm{differences} \mathrm{were} \mathrm{not} \mathrm{statistically}$ significant $(\mathrm{p}=0.069)$ between samples D40 and D50, but were significant between samples 
$\mathrm{L}$ and D60. These results may be due to the fact that the lyophilisation process takes place at low temperatures, avoiding as much as possible the degradation of the phenolic compounds, as compared with air drying (Figure 2). In the processes of drying in the chamber, the higher the temperature the smaller the amount of phenolic compounds present. In fact, as the temperature increased from $40{ }^{\circ} \mathrm{C}$ to $60^{\circ} \mathrm{C}$ the amount of total phenols quantified decreased in about 20\% (Figure 3). These results are in accordance with Santos et al. [11], who reported a decrease in the phenolic compounds of dried pears ranging from $28 \%$ to $44 \%$ in the peel and from $1 \%$ to $40 \%$ in the pulp, when the temperature increased also from $40{ }^{\circ} \mathrm{C}$ to $60{ }^{\circ} \mathrm{C}$. The value obtained by Falleh et al. [3] for thistle flower from the species C. Cardunculus L. grown in Tunisia for methanol extract was $6.96 \mathrm{mg} \mathrm{GAE} / \mathrm{g}$ (dry basis). This difference may be due to the drying process and operating conditions used, since the amount reported in the literature refers to thistle from an artisanal drying, at direct sunlight, and in this work the drying was by convective hot air drying or lyophilization, and hence under more controlled circumstances. Another factor that may originate the observed differences is the different origins of the thistle flower used in the two studies, respectively, Portugal and Tunisia. However, the most plausible explanation could be attributed to the extraction process used, as in the study described by Falleh et al. [3] a single extraction was performed and only during 30 min under agitation, while in the present case four extractions were performed (two with methanol and two with acetone) and lasting 1 hour each. The procedure adopted in this work, besides providing a much higher contact time, also allows a better extraction because of using two types of solvents, with different polarities, and hence, suitable for the dissolution of different molecules in the phenolic family. According to Maneses et al. [24] the type of phenols soluble in each of the solvents tested is different, because phenols include one or more hydroxyl groups (polar) attached directly to an aromatic ring (non-polar). This stereochemistry distinguishes phenols according to their polarity variance, being the yield of extraction 
strongly dependent on the nature of the solvent. Furthermore, the molecular size also seems to influence the yield of extraction, and methanol has been reported as more efficient for the extraction of lower molecular weight polyphenols while the higher molecular weight flavonols are better extracted with aqueous acetone [25].

The lyophilized thistle showed an amount of flavonoid compounds in the methanol extracts equal to $23.4 \mathrm{mg} \mathrm{QE} / \mathrm{g}$, a quantity $20 \%$ lower than the in the acetone extracts $(29.1 \mathrm{mg} \mathrm{QE} / \mathrm{g}$ sample) (Table 2). The amount of flavonoids in the methanol extracts represented on average $45 \%$ of the total extracted and in the acetone extracts the remaining $55 \%$. Because flavonoids are polar they are suitable for extraction with a polar solvent such as methanol [26]. However, the solubility of the phenols in each solvent is also very much dependent on the food matrix at study [27-29]. Comparing the different dryings, the total amount of flavonoids was in general similar (slightly over $50 \mathrm{mg} \mathrm{QE} / \mathrm{g}$ ), with exception for the drying at $40{ }^{\circ} \mathrm{C}$ which showed the lowest value (43.4 $\mathrm{mg} \mathrm{QE} / \mathrm{g}$ ) (Table 2). Still, it was possible to see that the sample D60 contained an amount of flavonoid compounds significantly $(p=0.000)$ superior to the other samples, as indicated by the statistical test, maybe due to higher resistance to temperature. Despite the different extraction conditions used, the results were of the same magnitude as the values for eight described genera of the family cynara by other authors [30] (1.9 to $3.3 \mathrm{~g}$ QE/100g of sample, corresponding to $19-33 \mathrm{mg} \mathrm{QE} / \mathrm{g}$ ).

The ortho-diphenolic compounds were preferably extracted by acetone (62-80\%) as compared to the methanol extracts (Table 2). The higher content of ortho-diphenols was observed for the lyophilized thistle (4.3 $\mathrm{mg} \mathrm{GAE} / \mathrm{g}$ ), whereas the lowest amount was in the thistle dried at 40 ${ }^{\circ} \mathrm{C}(1.8 \mathrm{mg} \mathrm{GAE} / \mathrm{g})$, with significant differences $(\mathrm{p}=0.000)$ between all dried samples. Furthermore, it was observed an increase in the contents of ortho-diphenols with increasing drying temperature: ortho-diphenols augmented from $1.8 \mathrm{mg}$ GAE/g to $3.5 \mathrm{mg}$ GAE/g for a temperature raise from $40{ }^{\circ} \mathrm{C}$ to $60{ }^{\circ} \mathrm{C}$. Also Santos et al. [11] reported some increase ranging 
from $7 \%$ to $23 \%$ in ortho-diphenols in the peel of dried pears, when the temperature increased from $40{ }^{\circ} \mathrm{C}$ to $60{ }^{\circ} \mathrm{C}$. This increase in the quantity of ortho-diphenols occurring with drying could be attributed to structural changes in the matrices of the product, which become less cohesive and more flaccid during drying, thus allowing a greater extraction of orthodiphenols, resulting in a higher amount in the samples dried at higher temperatures [31,32]. Also some reactions may occur during drying which originate ortho-diphenols, namely oxidation reactions [11].

The extracts obtained were purified and the fraction obtained used for the analysis of phenolic acids. HPLC analysis was performed at two wavelengths, 280 and $325 \mathrm{~nm}$, aimed at the identification of hydroxybenzoic acids, hydroxycinnamic acids and their derivatives in the first case, while the detection at $325 \mathrm{~nm}$ allowed only to identify the hydroxycinnamic acids, due to the presence of the double bond in the carbon chain.

From the analysis of the chromatograms it was possible to ascertain the presence of 44 compounds with retention times between 3.04 and 66.30 minutes. The methanol extract was less rich in phenolic acids compared with the acetone extract. The methanol extract showed 26 compounds with a total concentration of benzoic acids equal to $38.30 \mathrm{mg} / \mathrm{L}$ and of hydroxycinnamic acids equal to $81.07 \mathrm{mg} / \mathrm{L}$, while the acetone extract yielded 37 compounds corresponding to concentrations of 66.38 and $168.08 \mathrm{mg} / \mathrm{L}$ of benzoic and hydroxycinnamic acids, respectively. Comparing the results from the two extracts, it was found that the compounds present in both were basically the same.

Table 3 shows the amount $(\mathrm{mg} / \mathrm{g})$ of benzoic and hydroxycinnamic acids quantified in the methanolic and acetone:water extracts for all samples. The total phenolic compounds was $6,66 \mathrm{mg} / \mathrm{g}$ in the lyophilyzed sample, $4.87 \mathrm{mg} / \mathrm{g}$ in the sample dried at $40{ }^{\circ} \mathrm{C}, 4.78 \mathrm{mg} / \mathrm{g}$ for that dried at $50{ }^{\circ} \mathrm{C}$, and $1.77 \mathrm{mg} / \mathrm{g}$ for the sample dried at $60{ }^{\circ} \mathrm{C}$. The amount of phenolic acids 
quantified decreased with the increase in the drying temperature. The total amount quantified in the sample dried at $60^{\circ} \mathrm{C}$ represented $27 \%$ of the quantified in the lyophilyzed sample.

The amount of hydroxycinnamic acids represented between $74-89 \%$ of the total phenolic acids quantified, ranging from $5.59 \mathrm{mg} / \mathrm{g}$ for lyophilyzed sample to $1.57 \mathrm{mg} / \mathrm{g}$ for sample dried at $60^{\circ} \mathrm{C}$. The total amount quantified in the sample dried at $60^{\circ} \mathrm{C}$ represented $27 \%$ of the content quantified in the lyophilyzed sample.

Regarding the relative contribution of each extract, it was possible to observe different trends depending on the samples. For samples L, D40 and D50, acetone:water extracts contained higher amounts (51-76\%) of phenolic acids. Otherwise, for D60, the methanolic extract represented $88 \%$ of the phenolic acids quantified, for both benzoic and hydroxycinnamic acids.

Although the information about the phenolic composition of thistle is scarce in the literature, it was observed in the present work that the thistle flowers presented significant quantities of phenolic compounds. It was possible to identify some peaks, such as 5-O-caffeoylquinic acid (chlorogenic acid), which is described to exhibit antioxidant potential, increasing the resistance of LDL-cholesterol to lipid peroxidation and decreasing DNA damage [33].

Among the samples analysed, the sample dried at $50{ }^{\circ} \mathrm{C}$ was the richest in hydroxycinnamic acids, with a total concentration of $193.47 \mathrm{mg} / \mathrm{L}$, followed by the lyophilized sample, with $171.93 \mathrm{mg} / \mathrm{L}$. These two samples were also the richest in benzoic acids, with concentrations of $60.74 \mathrm{mg} / \mathrm{L}$ and $55.06 \mathrm{mg} / \mathrm{L}$, respectively.

\section{Antioxidant Activity}

Table 4 shows the antioxidant activity, expressed in mmol of trolox equivalents per gram of sample (mmol TE/g), using the ABTS and DPPH methods, for samples of thistle lyophilized (L) and dried at $40{ }^{\circ} \mathrm{C}(\mathrm{D} 40), 50{ }^{\circ} \mathrm{C}(\mathrm{D} 50)$ and $60{ }^{\circ} \mathrm{C}(\mathrm{D} 60)$. 
The highest antioxidant activity determined by ABTS method was in sample D50 (7.0 mmol TE/g), of which $74 \%$ was due to the contribution of the acetone extracts. However, this sample was not statistically different from sample L with $6.7 \mathrm{mmol} \mathrm{TE} / \mathrm{g}$. The lowest antioxidant activity was observed at $60{ }^{\circ} \mathrm{C}(4.4 \mathrm{mmol} \mathrm{TE} / \mathrm{g})$, for which the methanol extract contributed with $38 \%$. In general, the antioxidant activities by ABTS method were higher for the acetone extracts, with exception of sample D40, in which the acetone extract was responsible for $43 \%$ of the antioxidant activity. According to Gouveia and Castilho [34] the antioxidant activity determined by the ABTS method for thistle flower from Madeira was 419 $\mu \mathrm{mol} \mathrm{TE} / 100 \mathrm{~g}$ sample, much lower than the values obtained in this work.

The antioxidant activity values obtained by the analytical method DPPH are also presented in Table 4. Samples L, D40 and D50 showed very similar values $(32.9,33.9,30.9 \mathrm{mmol} \mathrm{TE} / \mathrm{g}$, respectively), while sample D60 showed the lowest antioxidant activity $(9.2 \mathrm{mmol} \mathrm{TE} / \mathrm{g}$ ), significantly different form the other samples, being $72 \%$ less compared with the antioxidant power of the sample of lyophilized thistle. This lower value is in agreement with the least amount of phenolic compounds present in that sample. Several authors described a positive correlation between the content of phenolic compounds and antioxidant activity of different samples [35,36]. Gouveia and Castilho [34] reported values of antioxidant activity by the DPPH method for the thistle flower from Madeira lower than those presented in this study.

Comparing with the results obtained by the ABTS method, the antioxidant activity determined by the DPPH method was much higher than that evaluated by the ABTS method ( 2 to 6 times higher). The differences found in antioxidant activity by these two methods resides in the fact that DPPH and ABTS radicals have different sensibilities [37]. 


\section{Bioavailability}

Table 5 presents the bioavailability of the phenolic compounds for the in vitro simulation of the conditions along the digestive tract: mouth, stomach and intestine. The results for the methanolic extracts showed that the amount of phenolic compounds decreased along the digestive systems. The remaining phenolic compounds after simulation of the mouth, comprised up to $84 \%$ of the initial amount quantified. After stomach simulation, the remaining phenolic compounds comprised between $52 \%$ for the lyophilyzed sample and $68 \%$ for the sample dried at $60^{\circ} \mathrm{C}$.

At the end of the digestive tract, the higher decrease occurred for the sample D40, remaining only $38 \%$ of the original (Figure 4). The amount of phenolic compounds in the methanol extracts represented 42 and 37\%, for L and D40, respectively. Sample D60 showed a degradation of only $15 \%$ in the phenolic compounds during the various stages of the digestive tract (Figure 4). These results showed that stomach was the main responsible for the decrease on the phenolic compounds available. This is in accordance with Bouayed et al., [38], who showed that the release of polyphenols from apples following simulated gastrointestinal digestion was mainly achieved during the gastric phase.

The values of bioavailability for the acetone extracts are also shown in Table 5. Samples L and D40 showed a similar pattern as that for the methanol extracts for the same samples. However, for both samples the degree of degradation was less as compared to the methanol extracts, remaining 58\% and 39\%, respectively for L and D40 samples in the acetone extracts as compared to $42 \%$ and $37 \%$ in the methanol extracts after whole simulation of digestive track. With regard to the sample dried at $50{ }^{\circ} \mathrm{C}$, the whole losses along the digestive tract were much less, so that after the whole simulations there were still $85 \%$ of the phenolic compounds in the acetone extract available. Also sample D60 revealed a very high resistance to the conditions of the digestive tract, not degrading the phenolic compounds, and thus 
preserving their bioavailability. A slight increase in the phenolic compounds quantified was observed in the acetone extract on the thistle sample dried at $60^{\circ} \mathrm{C}$. According to Bouayed et al., [38] the increase of phenolic compounds after digestion in the small intestine may be related to the effect of the enzymes (lipase, amylase and pancreatin or protease activity) in the food matrix, facilitating the release of the phenolic compounds bound to the matrix.

In general, the phenolic compounds present in the acetone extracts showed to be more resistant to the action of the enzymes present in the digestive track, when compared with those presented in the methanolic extracts.

Table 5 also shows the global variation of phenolic compounds along the digestive system, considering the average between both extracts. For the sample D40, only $38 \%$ of the phenolic compounds were still available for absorption in the intestine, being the lowest value among all samples analysed. In both samples D50 and lyophilized the phenolic compounds decreased to $50 \%$ of the initial amount when reaching the intestine. The results for sample D60 reveal that a very large fraction of the phenolic compounds initially present were still available when reaching the intestine $(86 \%)$, thus indicating that these compounds, which resisted the higher temperature, also resisted in a high degree to the action of the solutions used to simulate the digestive tract (Figure 4). According to a study by Cilia et al., [39], after the intake of fruit juices the digestive process reduced the phenolic compounds by about $47 \%$ of the initial content. Another study by Tagliazucchi et al. [40] demonstrated that the grapes after intestinal digestion, lost about $38 \%$ of the total phenolic compounds. Although for different food matrices, the final percentage of phenolic compounds available for potential intestinal absorption found by Bouayed et al., [38], Cilia et al., [39] and Tagliazucchi et al. [40] were similar to that obtained for the thistle extract. 


\section{Sugar composition}

The different dried thistle samples were used to analyse the neutral sugars constituents of the polysaccharides. Table 6 shows the total amount of monosaccharides quantified, as well the molar composition for all the thistle samples analysed. The total amount of sugars quantified for lyophilized sample was $222 \mathrm{mg} / \mathrm{g}$, and it was the highest value comparing with the oven dried samples. As a higher drying temperature was used, lower amount of sugars were quantified, ranging from $179.1 \mathrm{mg} / \mathrm{g}$ for sample dried at $40{ }^{\circ} \mathrm{C}$ to $101.6 \mathrm{mg} / \mathrm{g}$ for sample dried at $60{ }^{\circ} \mathrm{C}$. This decrease was mainly due a decrease of the amount of uronic acids and glucose. The lower content in sugars with the higher drying temperature can be due to the promotion of reactions with the temperature, such as the Maillard reactions. From the composition of the various identified monosaccharides is possible to propose a structure for the constituent polysaccharides in the thistle flower [41]. The uronic acid was the sugar residue present in higher proportions $(56.7-68.4 \mathrm{~mol} \%)$ whereas rhamnose comprised 0.7 to $3.3 \mathrm{~mol} \%$, allowing to infer the presence of rhamnogalacturonans. These results are in accordance with those reported in filament and corolla of tristle by Marga et al. [42]. The relative amount of arabinose was 9.4 mol\% in the lyophilyzed sample, which was lower when compared with the oven dried samples (12.6 -18.6 mol\%). The presence of arabinose and galactose should also be related with pectic polysaccharides, which have in their structure arabinogalactans. The presence of xylose $(3.5-4.4 \mathrm{~mol} \%)$ may be due the presence of xylans. The glucose represented 13.6 to $16.6 \mathrm{~mol} \%$, and can be derived from polysaccharides such as cellulose but also can be due to a monomeric glucose contribution.

\section{Conclusions}

The results from this work showed that to obtain a dried thistle flower with a minimal moisture content compatible with good conservation, it took about 3 hours at $60{ }^{\circ} \mathrm{C}, 4$ hours at 
$50{ }^{\circ} \mathrm{C}$ and 5 hours and a half at $40^{\circ} \mathrm{C}$. Sugar analysis revealed the presence of monosaccharides constituents of pectic polysaccharides, xylans and cellulose. However, it is important to make a detailed structural characterization of polysaccharides present in order to know the nature of the polysaccharides and their role in the thistle, as well as their potential applications.

The lyophilized thistle flower presented $18.5 \mathrm{mg}$ GAE/g of total phenolic compounds and 4.3 mg GAE/g ortho-diphenols, whereas the oven drying originated a decrease in the contents as the drying temperature increased. On the other hand, the amount of flavonoids was similar regardless of the drying conditions.

The antioxidant activity was much different depending on the method used for quantification, with DPPH values always higher than ABTS. When comparing the different dryings, the antioxidant activity was lower for $60^{\circ} \mathrm{C}$. Still, the thistle flower has phenolic compounds that have preserved most of their antioxidant activity after the drying processes to which they were submited.

After passing through an in vitro model simulating the digestive tract, $38 \%$ to $86 \%$ of the phenolic compounds present remained available to be absorbed in the intestine.

\section{Acknowledgement}

This work was done in the ambit of a master thesis in Food Quality and Technology from Polytechnic Institute of Viseu and the Research Centre CI\&DETS.

\section{References}

1. S. Umar Lule and W. Xia, Food Rev. Int. 21, 367 (2005).

2. M. de L. R. Giada, in Oxidative Stress Chronic Degener. Dis. - Role Antioxid. (IMTECH, Rijeka, Croatia, 2013), pp. 87-112.

3. H. Falleh, R. Ksouri, K. Chaieb, N. Karray-Bouraoui, N. Trabelsi, M. Boulaaba, and C. Abdelly, C. R. Biol. 331, 372 (2008). 
4. C. A. Rice-Evans and L. Packer, Flavonoids in Health and Disease, 2nd. (CRC Press, USA, 2003).

5. A. S. T. Pedro, Estudo de Compostos Com Propriedades Funcionais Em Flor de Cardo Submetida a Diferentes Tratamentos de Secagem. Dissertação Do Mestrado Em Qualidade E Tecnologia Alimentar. (ESAV, Viseu, Portugal, 2013).

6. A. Karkanis, D. Bilalis, and A. Efthimiadou, Ind. Crops Prod. 34, 825 (2011).

7. A. Figueirinha, M. T. Cruz, V. Francisco, M. C. Lopes, and M. T. Batista, J. Med. Food 13, $681(2010)$.

8. V. Francisco, A. Figueirinha, G. Costa, J. Liberal, M. C. Lopes, C. García-Rodríguez, C. F. G. C. Geraldes, M. T. Cruz, and M. T. Batista, J. Funct. Foods 10, 436 (2014).

9. R. P. F. Guiné, M. J. Barroca, F. J. Gonçalves, M. Alves, S. Oliveira, and M. Mendes, Food Chem. 168, 454 (2015).

10. J. Liberal, V. Francisco, G. Costa, A. Figueirinha, M. T. Amaral, C. Marques, H. Girão, M. C. Lopes, M. T. Cruz, and M. T. Batista, J. Ethnopharmacol. 158, Part A, 113 (2014).

11. S. C. R. V. L. Santos, R. P. F. Guiné, and A. Barros, J. Food Meas. Charact. 8, 105 (2014).

12. R. P. F. Guiné, D. M. S. Ferreira, M. J. Barroca, and F. M. Gonçalves, Biosyst. Eng. 98, 422 (2007).

13. M. A. Coimbra, C. Nunes, P. R. Cunha, and R. Guiné, Eur. Food Res. Technol. 233, 637 (2011).

14. R. P. F. Guiné, I. C. Almeida, A. C. Correia, and F. J. Gonçalves, J. Food Meas. Charact. 9, 337 (2015).

15. S. Soutinho, R. P. F. Guiné, A. Jordão, and F. Gonçalves, J. Biol. Vet. Agric. Food Eng. 7, 535 (2013).

16. R. P. F. Guiné, S. M. A. Soutinho, and F. J. Gonçalves, Croat. J. Food Sci. Technol. 6, 15 (2014).

17. G. J. McDougall, S. Fyffe, P. Dobson, and D. Stewart, Phytochemistry 66, 2540 (2005).

18. C. Nunes, J. A. Saraiva, and M. A. Coimbra, Food Chem. 111, 538 (2008).

19. F. Lian, W. Zhao, R. Yang, Y. Tang, and W. Katiyo, Food Control 47, 1 (2015).

20. K. Prabhakar and E. N. Mallika, in Encycl. Food Microbiol., edited by C. A. B. L. Tortorello (Academic Press, Oxford, 2014), pp. 751-754.

21. E. Maltini, D. Torreggiani, E. Venir, and G. Bertolo, Food Chem. 82, 79 (2003).

22. J. M. D. Matos, Estudo Da Secagem Da Flor de Cardo E Análise de Polissacarídeos E Compostos Fenólicos. Dissertação Do Mestrado Em Qualidade E Tecnologia Alimentar. (ESAV, Viseu, Portugal, 2014). 
23. S. M. Santillana Farakos, J. F. Frank, and D. W. Schaffner, Int. J. Food Microbiol. 166, $280(2013)$.

24. N. G. T. Meneses, S. Martins, J. A. Teixeira, and S. I. Mussatto, Sep. Purif. Technol. 108, $152(2013)$.

25. J. Dai and R. J. Mumper, Mol. Basel Switz. 15, 7313 (2010).

26. N. Rispail, P. Morris, and K. J. Webb, in Lotus Jpn. Handb., Márquez A.J. (Springer, The Netherlands, 2005), pp. 349-355.

27. J. A. Michiels, C. Kevers, J. Pincemail, J. O. Defraigne, and J. Dommes, Food Chem. 130, 986 (2012).

28. L. Tomsone, Z. Kruma, and R. Galoburda, World Acad. Sci. Eng. Technol. 64, 903 (2012).

29. K. Zhou and L. Yu, LWT - Food Sci. Technol. 37, 717 (2004).

30. D. Zheleva-Dimitrova, I. Zhelev, and I. Dimitrova-Dyulgerova, Free Radic. Antioxid. 1, 15 (2011).

31. C. T. Brett and K. W. Waldron, Physiology and Biochemistry of Plant Cell Walls, 2nd ed. (Springer, New York, 1996).

32. D. Ferreira, J. A. L. da Silva, G. Pinto, C. Santos, I. Delgadillo, and M. A. Coimbra, Eur. Food Res. Technol. 226, 1545 (2007).

33. M.-P. Gonthier, M.-A. Verny, C. Besson, C. Rémésy, and A. Scalbert, J. Nutr. 133, 1853 (2003).

34. S. C. Gouveia and P. C. Castilho, Food Res. Int. 48, 712 (2012).

35. V. Katalinić, M. Milos, D. Modun, I. Musić, and M. Boban, Food Chem. 86, 593 (2004).

36. J. Lachman, M. Šulc, and M. Schilla, Food Chem. 103, 802 (2007).

37. M. B. Arnao, Trends Food Sci. Technol. 11, 419 (2000).

38. J. Bouayed, L. Hoffmann, and T. Bohn, Food Chem. 128, 14 (2011).

39. A. Cilla, A. González-Sarrías, F. A. Tomás-Barberán, J. C. Espín, and R. Barberá, Food Chem. 114, 813 (2009).

40. D. Tagliazucchi, E. Verzelloni, D. Bertolini, and A. Conte, Food Chem. 120, 599 (2010).

41. C. Rosenbohm, I. Lundt, T. I. E. Christensen, and N. G. Young, Carbohydr. Res. 338, 637 (2003).

42. F. Marga, A. Gallo, and K. H. Hasenstein, Plant Physiol. Biochem. 41, 792 (2003). 


\section{Tables}

Table 1. Evaluation of phenolic compounds and antioxidant activity in the different extracts.

\begin{tabular}{|c|c|c|c|c|c|}
\hline & \multirow[b]{3}{*}{ Extract } & \multicolumn{4}{|c|}{ Sample mass to solvent ratio (g:mL) } \\
\hline & & \multicolumn{2}{|c|}{$5: 50$} & \multicolumn{2}{|c|}{$10: 50$} \\
\hline & & Methanol & Acetone & Methanol & Acetone \\
\hline Total phenols & 1st extraction & $5.2( \pm 0.2)^{\mathrm{a}}$ & $3.3( \pm 0.0)^{b}$ & $3.0( \pm 0.0)^{\mathrm{b}}$ & $4.8( \pm 0.0)^{\mathrm{a}}$ \\
\hline \multirow[t]{2}{*}{ (mg GAE/g) } & 2nd extraction & $3.2( \pm 0.1)^{\mathrm{a}}$ & $1.5( \pm 0.0)^{\mathrm{b}}$ & $1.8( \pm 0.0)^{\mathrm{a}}$ & $1.6( \pm 0.0)^{\mathrm{b}}$ \\
\hline & Total & \multicolumn{2}{|c|}{$13.2( \pm 0.2)^{\mathrm{A}}$} & \multicolumn{2}{|c|}{$11.2( \pm 0.0)^{\mathrm{B}}$} \\
\hline Antioxidant activity (DPPH) & 1st extraction & $3.4( \pm 0.1)^{\mathrm{b}}$ & $4.1( \pm 0.1)^{\mathrm{a}}$ & $3.8( \pm 0.1)^{\mathrm{a}}$ & $1.9( \pm 0.1)^{b}$ \\
\hline \multirow[t]{2}{*}{$(\mathrm{mmol} \mathrm{TE} / \mathrm{g})$} & 2nd extraction & $1.3( \pm 0.0)^{\mathrm{a}}$ & $0.8( \pm 0.1)^{\mathrm{b}}$ & $2.0( \pm 0.0)^{\mathrm{a}}$ & $0.9( \pm 0.1)^{\mathrm{b}}$ \\
\hline & Total & \multicolumn{2}{|c|}{$9.6( \pm 0.1)^{\mathrm{A}}$} & \multicolumn{2}{|c|}{$8.6( \pm 0.1)^{B}$} \\
\hline
\end{tabular}

Different lowercase letters in the same row indicate statistical significant differences between solvents for each sample mass considered ( $T$ de student test, $\mathrm{p}<0.05$ ).

Different uppercase letters in the same row indicate statistical significant differences between sample masses for the total values ( $\mathrm{T}$ de student test, $\mathrm{p}<0.05$ ). 
Table 2. Phenolic compounds of the thistle samples dried under different conditions.

\begin{tabular}{llcccc}
\hline & & \multicolumn{4}{c}{ Samples $^{*}$} \\
\cline { 3 - 6 } & Extract & \multicolumn{1}{c}{$\mathbf{L}$} & D40 & D50 & D60 \\
\hline Total phenols & Methanol & $12.8( \pm 1.3)^{\mathrm{a}}$ & $6.3( \pm 0.4)^{\mathrm{b}}$ & $6.1( \pm 0.1)^{\mathrm{b}}$ & $4.3( \pm 0.1)^{\mathrm{c}}$ \\
$(\mathrm{mg} \mathrm{GAE} / \mathrm{g})$ & Acetone & $5.7( \pm 0.1)^{\mathrm{d}}$ & $6.3( \pm 0.1)^{\mathrm{b}}$ & $6.6( \pm 1.1)^{\mathrm{a}}$ & $5.9( \pm 0.0)^{\mathrm{c}}$ \\
& Total & $\mathbf{1 8 . 5}( \pm 1.4)^{\mathrm{a}}$ & $\mathbf{1 2 . 6}( \pm 0.3)^{\mathrm{b}}$ & $\mathbf{1 2 . 7}( \pm 1.2)^{\mathrm{b}}$ & $\mathbf{1 0 . 2}( \pm 0.1)^{\mathrm{c}}$ \\
\hline Flavonoids & Methanol & $23.4( \pm 2.3)^{\mathrm{b}}$ & $16.1( \pm 3.9)^{\mathrm{c}}$ & $25.6( \pm 1.1)^{\mathrm{a}}$ & $26.2( \pm 1.1)^{\mathrm{a}}$ \\
$($ mg QE/g) & Acetone & $29.1( \pm 1.9)^{\mathrm{a}}$ & $27.3( \pm 1.7)^{\mathrm{b}}$ & $26.3( \pm 1.2)^{\mathrm{b}}$ & $28.0( \pm 1.9)^{\mathrm{a}}$ \\
& Total & $\mathbf{5 2 . 5}( \pm 0.4)^{\mathrm{b}}$ & $\mathbf{4 3 . 4}( \pm 4.3)^{\mathrm{c}}$ & $\mathbf{5 1 . 9}( \pm 0.1)^{\mathrm{b}}$ & $\mathbf{5 4 . 2}( \pm 0.8)^{\mathrm{a}}$ \\
\hline Ortho-diphenols & Methanol & $0.9( \pm 0.1)^{\mathrm{b}}$ & $0.7( \pm 0.0)^{\mathrm{c}}$ & $0.5( \pm 0.1)^{\mathrm{d}}$ & $1.4( \pm 0.4)^{\mathrm{a}}$ \\
$($ mg GAE/g) & Acetone & $3.4( \pm 0.1)^{\mathrm{a}}$ & $1.1( \pm 0.1)^{\mathrm{c}}$ & $2.2( \pm 0.3)^{\mathrm{b}}$ & $2.1( \pm 0.5)^{\mathrm{b}}$ \\
& Total & $\mathbf{4 . 3}( \pm 0.0)^{\mathrm{a}}$ & $\mathbf{1 . 8}( \pm 0.0)^{\mathrm{d}}$ & $\mathbf{2 . 7}( \pm 0.3)^{\mathrm{c}}$ & $\mathbf{3 . 5}( \pm 0.1)^{\mathrm{b}}$ \\
\hline
\end{tabular}

${ }^{*} \mathrm{~L}$ - lyophilyzed, D40 - dried at $40^{\circ} \mathrm{C}$, D50 - dried at $50{ }^{\circ} \mathrm{C}$, D60 - dried at $60^{\circ} \mathrm{C}$.

Different letters in the same row indicate statistical significant differences between drying conditions (ANOVA, with Tukey post-hoc, $\mathrm{p}<0.05$ ). 
Table 3. Phenolic compounds ( $\mathrm{mg} / \mathrm{g}$ ) of the thistle samples dried under different conditions.

\begin{tabular}{|c|c|c|c|c|c|c|c|c|}
\hline \multirow{3}{*}{ Extract } & \multicolumn{6}{|c|}{ Samples* } & & \\
\hline & \multicolumn{2}{|c|}{$\mathbf{L}$} & \multicolumn{2}{|c|}{ D40 } & \multicolumn{2}{|c|}{ D50 } & \multicolumn{2}{|c|}{ D60 } \\
\hline & B.A. & H.A. & B.A. & H.A. & B.A. & H.A. & B.A. & H.A. \\
\hline Methanol & 0,52 & 2,51 & 0,51 & 1,24 & 0,14 & 1,03 & 0,17 & 1,39 \\
\hline Acetone & 0,55 & 3,08 & 0,75 & 2,37 & 0,38 & 3,22 & 0,02 & 0,19 \\
\hline Total & 1,07 & 5,59 & 1,26 & 3,61 & 0,52 & 4,26 & 0,19 & 1,57 \\
\hline
\end{tabular}

${ }^{*} \mathrm{~L}$ - lyophilyzed, D40 - dried at $40^{\circ} \mathrm{C}$, D50 - dried at $50{ }^{\circ} \mathrm{C}$, D60 - dried at $60^{\circ} \mathrm{C}$,

B.A. -benzoic acids, H.A.- hydroxycinnamic acids. 
Table 4. Antioxidant activity of the thistle samples dried under different conditions.

\begin{tabular}{llcccc}
\hline & & \multicolumn{4}{c}{ Samples $^{*}$} \\
\cline { 3 - 6 } & Extract & L & D40 & D50 & D60 \\
\hline Antioxidant activity - ABTS & Methanol & $1.5( \pm 0.2)^{\mathrm{d}}$ & $3.1( \pm 0.3)^{\mathrm{a}}$ & $1.8( \pm 0.0)^{\mathrm{b}}$ & $1.7( \pm 0.2)^{\mathrm{c}}$ \\
& Acetone & $5.2( \pm 0.5)^{\mathrm{a}}$ & $2.4( \pm 0.4)^{\mathrm{b}}$ & $5.2( \pm 0.7)^{\mathrm{a}}$ & $2.7( \pm 0.4)^{\mathrm{b}}$ \\
& Total & $\mathbf{6 . 7}( \pm 0.7)^{\mathrm{a}}$ & $\mathbf{5 . 5}( \pm 0.1)^{\mathrm{b}}$ & $\mathbf{7 . 0}( \pm 0.7)^{\mathrm{a}}$ & $\mathbf{4 . 4}( \pm 0.3)^{\mathrm{c}}$ \\
\hline Antioxidant activity - DPPH & Methanol & $15.8( \pm 0.7)^{\mathrm{a}}$ & $16.8( \pm 0.6)^{\mathrm{a}}$ & $16.1( \pm 0.3)^{\mathrm{a}}$ & $3.6( \pm 0.0)^{\mathrm{b}}$ \\
& Acetone & $17.1( \pm 1.2)^{\mathrm{a}}$ & $16.2( \pm 0.4)^{\mathrm{b}}$ & $14.8( \pm 0.2)^{\mathrm{c}}$ & $5.6( \pm 0.0)^{\mathrm{d}}$ \\
\cline { 3 - 6 } & Total & $\mathbf{3 2 . 9}( \pm 0.5)^{\mathrm{a}}$ & $\mathbf{3 3 . 0}( \pm 1.0)^{\mathrm{a}}$ & $\mathbf{3 0 . 9}( \pm 0.4)^{\mathrm{b}}$ & $\mathbf{9 . 2}( \pm 0.0)^{\mathrm{c}}$ \\
& & &
\end{tabular}

L - lyophilyzed, D40 - dried at $40{ }^{\circ} \mathrm{C}$, D50 - dried at $50{ }^{\circ} \mathrm{C}$, D60 - dried at $60^{\circ} \mathrm{C}$.

Different letters in the same row indicate statistical significant differences between drying conditions (ANOVA, with Tukey post-hoc, $\mathrm{p}<0.05$ ). 
Table 5. Variation of total phenolic compounds along the digestive system, according to extracting solvent.

\begin{tabular}{clcccc}
\hline \multirow{2}{*}{ Remaining total phenols (\%) } & Extract & L & D40 & D50 & \multicolumn{1}{c}{ D60 } \\
\cline { 3 - 6 } Mouth & Methanol & $84.0 \%$ & $94.0 \%$ & $109.0 \%$ & $92.0 \%$ \\
& Acetone & $92.0 \%$ & $95.0 \%$ & $109.0 \%$ & $107.0 \%$ \\
\cline { 2 - 6 } & Global & $\mathbf{8 8 . 0 \%}$ & $\mathbf{9 4 . 5 \%}$ & $\mathbf{1 0 9 . 0 \%}$ & $\mathbf{9 9 . 5 \%}$ \\
\hline \multirow{2}{*}{ Stomach } & Methanol & $42.0 \%$ & $52.0 \%$ & $54.0 \%$ & $68.0 \%$ \\
& Acetone & $68.0 \%$ & $48.0 \%$ & $89.0 \%$ & $101.0 \%$ \\
\cline { 2 - 6 } & Global & $\mathbf{5 5 . 0 \%}$ & $\mathbf{5 0 . 0 \%}$ & $\mathbf{7 1 . 5 \%}$ & $\mathbf{8 4 . 5 \%}$ \\
\hline \multirow{2}{*}{ Intestine } & Methanol & $42.0 \%$ & $37.0 \%$ & $15.0 \%$ & $51.0 \%$ \\
& Acetone & $58.0 \%$ & $39.0 \%$ & $85.0 \%$ & $120.0 \%$ \\
\cline { 2 - 6 } & Global & $\mathbf{5 0 . 0 \%}$ & $\mathbf{3 8 . 0 \%}$ & $\mathbf{5 0 . 0 \%}$ & $\mathbf{8 5 . 5 \%}$ \\
\hline
\end{tabular}

${ }^{*} \mathrm{~L}$ - lyophilyzed, D40 - dried at $40{ }^{\circ} \mathrm{C}, \mathrm{D} 50$ - dried at $50{ }^{\circ} \mathrm{C}, \mathrm{D} 60-\operatorname{dried}$ at $60{ }^{\circ} \mathrm{C}$. 
Table 6. Monosaccharides composition of the thistle samples studied.

\begin{tabular}{lcccc}
\hline & \multicolumn{4}{c}{ Samples* $^{*}$} \\
\cline { 2 - 5 } & L & D40 & D50 & D60 \\
\hline Total Sugars (mg/g) & 222.0 & 179.1 & 108.8 & 101.6 \\
\hline $\begin{array}{c}\text { Sugar composition (mol\%) } \\
\text { Rhamnose (Rha) }\end{array}$ & 0.7 & 3.3 & 2.2 & 2.4 \\
Arabinose (Ara) & 9.4 & 12.6 & 17.6 & 18.6 \\
Xylose (Xyl) & 3.5 & 3.8 & 4.2 & 4.4 \\
Mannose (Man) & 0.8 & 0.9 & 0.2 & 0.3 \\
\hline Galactose (Gal) & 2.1 & 2.2 & 2.2 & 3.3 \\
\hline Glucose (Clc) & 15.1 & 16.6 & 13.6 & 14.3 \\
\hline Uronic acids (UA) & 68.4 & 60.6 & 59.9 & 56.7 \\
\hline * L - lyophilyzed, D40 - dried at $40^{\circ} \mathrm{C}$, D50 - dried at $50^{\circ} \mathrm{C}, \mathrm{D} 60-$ dried at $60^{\circ} \mathrm{C}$.
\end{tabular}




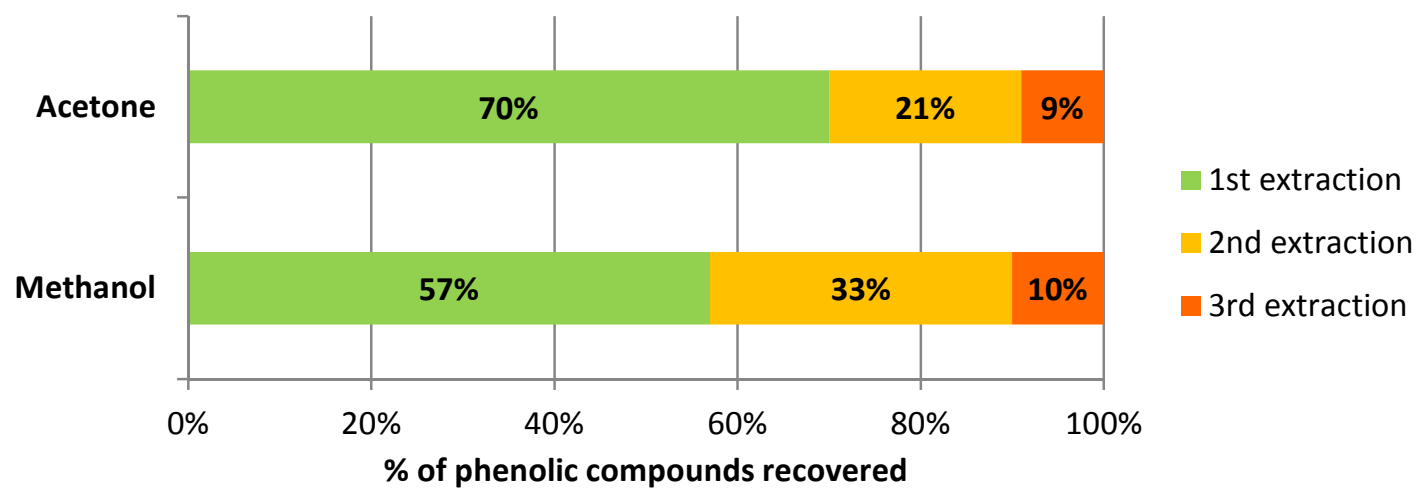

Figure 1. Percentages of recovery of phenolic compounds according to the order of the extracts. 
$\square$ Lyophilized $\square$ Air dried (40 ㅇ)

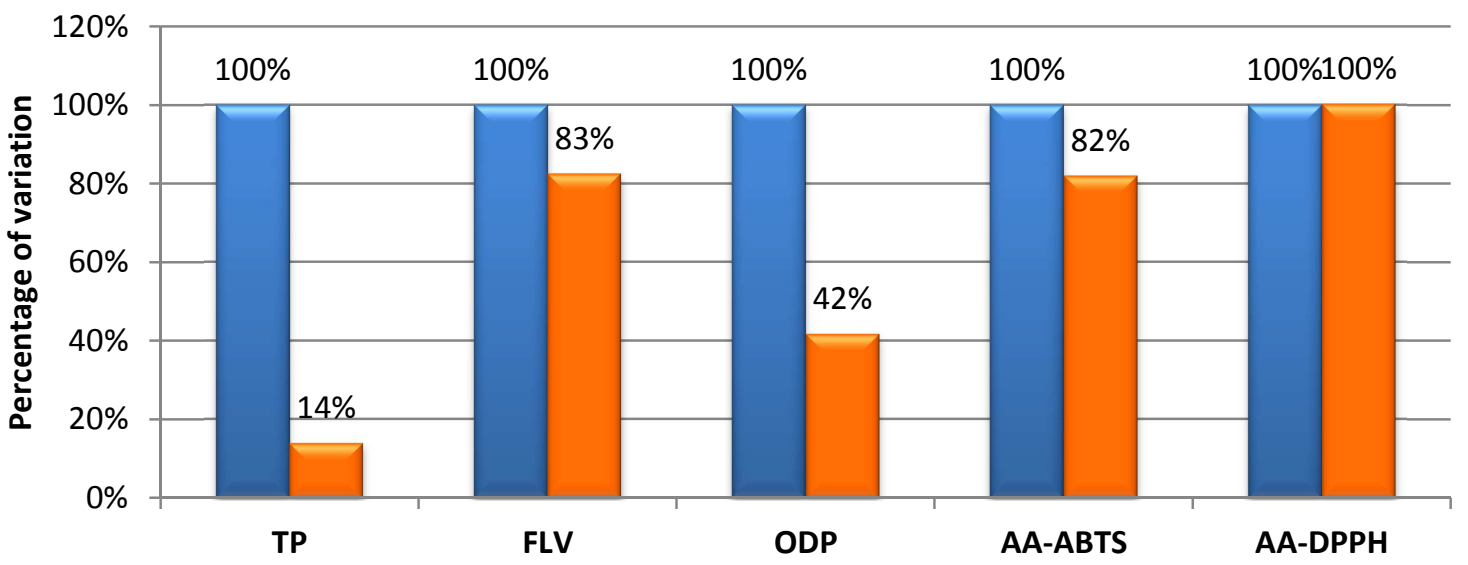

Figure 2. Percentages of variation of the compounds evaluated and antioxidant activity comparing lyophilization with air drying at the lowest temperature $(\mathrm{TP}=$ total phenols; FLV = flavonoids; ODP = ortho-diphenols; AA-ABTS $=$ antioxidant activity by ABTS method; AA-DPPH = antioxidant activity by DPPH method). 


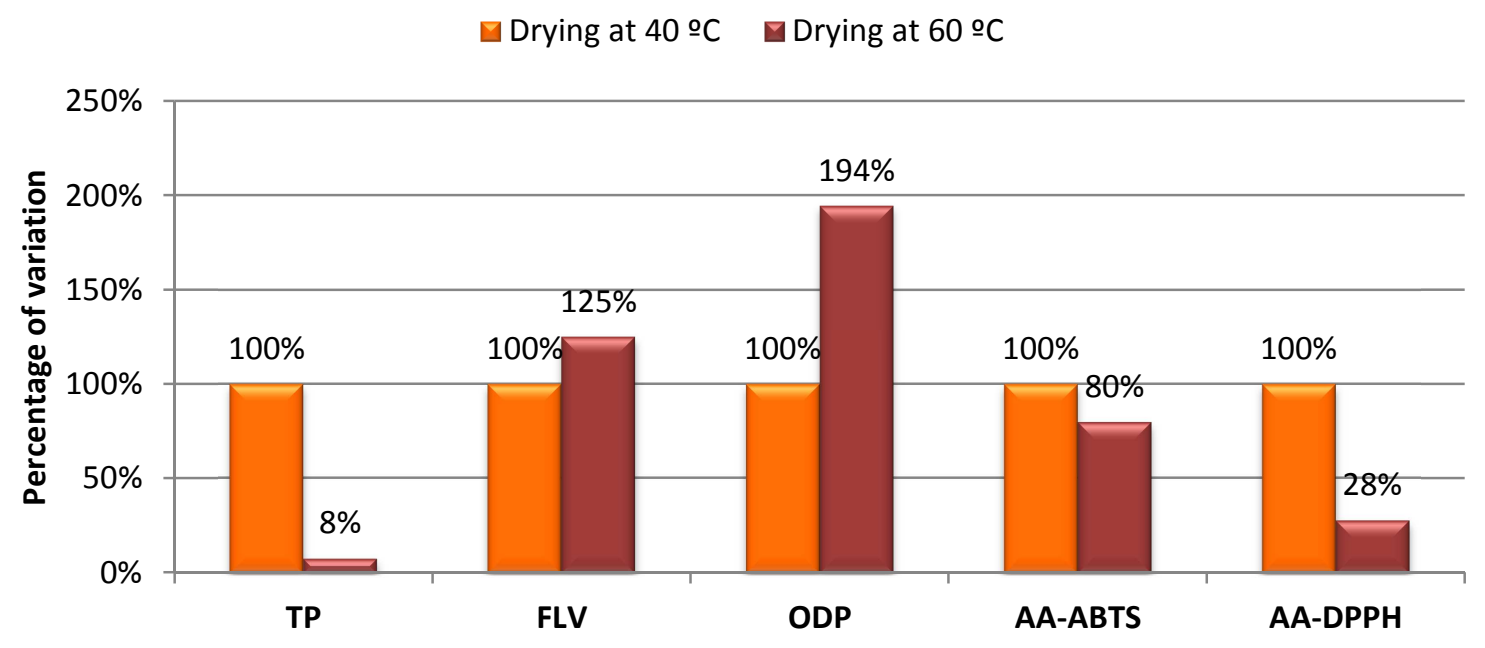

Figure 3. Percentages of variation of the compounds evaluated and antioxidant activity comparing the treatments with air drying at the lowest and highest temperatures $(\mathrm{TP}=$ total phenols; FLV $=$ flavonoids; ODP = ortho-diphenols; AA-ABTS = antioxidant activity by ABTS method; AA-DPPH = antioxidant activity by DPPH method). 


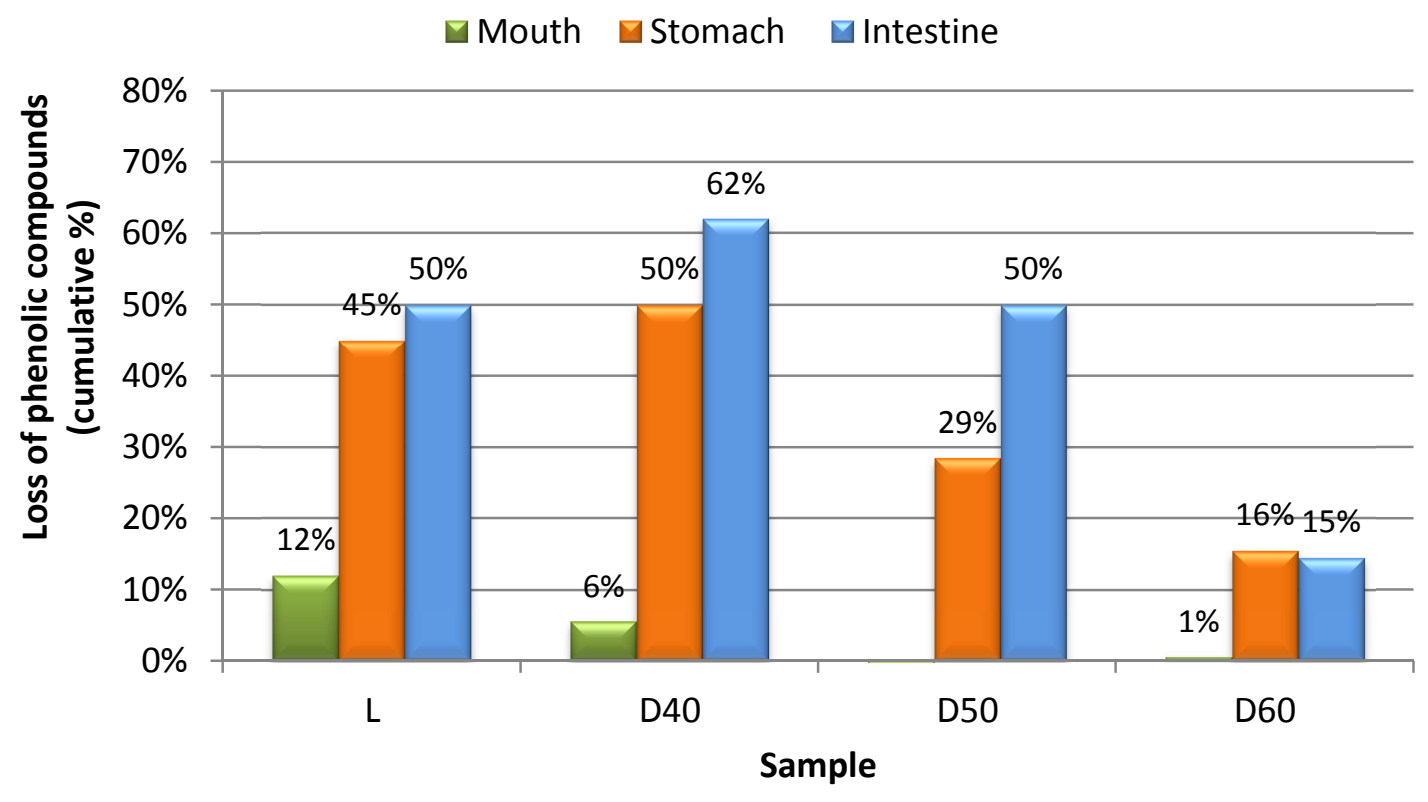

Figure 4. Decrease of phenolic compounds along the digestive system $(\mathrm{L}=$ lyophilized; $\mathrm{D} 40=$ air dried at $40{ }^{\circ} \mathrm{C}$; D50 $=$ air dried at $50{ }^{\circ} \mathrm{C} ; \mathrm{D} 60=$ air dried at $60{ }^{\circ} \mathrm{C}$ ). 